\section{Continued from previous page}

ing to MRS Past President Elton Kaufmann of the Lawrence Livermore National Laboratory. Kaufmann is 1986 Chair of the MRS Long-Range Planning Committee, a position assumed by each MRS past president as required by the Society's By-Laws.

Kaufmann noted that, "this year the committee will tackle a dozen different questions, some of which are new and some continuing from last year's com mittee directed by Woody White. A subcommittee comprised of from three to five members including a chairperson will focus on each issue. Kathy Taylor (MRS first vice president) of Ceneral Motors will lead the effort to update the Society's "Five-Year Projection," a task which involves estimating the type and volume of activity in which MRS will be involved through the year 1991. Judging the future trends in the context of balance among the several Society programs (such as topical symposia, short courses, publishing, etc.) will be the task of a group chaired by Clyde Northrup (1982 MRS president) of Sandia National Laboratories.

"Woody White will spearhead the continuation from last year of the development of options for the expansion of MRS headquarters facilities and its possible relocation. Forecasting of the role to be played by the U.S.-based MRS in the developing "MRS International" and defining the present directions which will lead to that role falls to a subcommittee led by David Biegelsen of Xerox PARC, who has just completed a magnificent job as a meeting chair for the annual MRS Fall Meeting in Boston. Dave will coordinate his efforts very closely with the MRS External Affairs Committee which oversees our international relations on an on-going basis."

Kaufmann explained that he will personally chair the subcommittee which will examine the question of new and/or modified awards and other forms of recognition which the Society may confer on individuals and groups in the materials research community. He emphasized," In this way the long-range plans and the current work of the MRS Awards Committee, which is also chaired by the past president, will be closely coordinated."

"In addition, potential new sources of revenue for the support of MRS programs are to be studied under the direction of MRS Treasurer Clif Draper of AT\& T Technologies and this is closely related to the work to be led by L. Ralph Dawson of Sandia National Laboratories concerning MRS relations with its program sponsors. Richard Schwoebel, also of Sandia, will bring his experience as a former MRS secretary and last year's chair of the External Affairs Committee to bear on the implications for MRS of the developing collaborative relationships MRS now enjoys and may enjoy in the future with other technical societies. The welcome increasingly active involvement of university faculty in the affairs of the MRS will continue to be watched by a group led by Rustum Roy of Penn State, with an eye toward facilitating this healthy trend.

"The operational structures and procedures of the MRS Council and of MRS committees will be examined from the standpoint of their present efficiency and robustness for the future in an ever larger and more complex MRS. The Council and committees aspects will be studied by two different groups led respectively by Fred Young, Jr. of Oak Ridge National Laboratory and a Councillor himself, and by Woody White, also of ORNL and 1984 MRS president.

"Finally," Kaufmann concluded, "we are watching current organizational trends in elect ronically aided communication and data retrieval and will develop proposals for ways MRS might benefit from the implementation of such functions as telemail, bulletin boards, and data bases. Paul Peercy of Sandia, last year's MRS Program Committee chair, will lead this investigation. The full Long-Range Planning Committee has its work cut out. It will greatly benefit not only from the efforts of all of the subcommittee members, but also from insights on the future of our Society and of our field cont ributed by all of our members." Members interested in sharing their views in any of the above mentioned areas, should contact one of the subcommittee chairs or Elton Kaufmann.

\title{
Versailles Materials Project Moves Toward Independence
}

At the June 1982 Economic Summit of Versailles, seven heads of state and government, together with representatives of the European Community (EEC), proposed 18 separate technical projects to help summit members promote "the development of and trade in new technologies." In almost four years since that summit, the Versailles Project on Advanced Materials and Materials Standards (VAMAS) has grown into a $\$ 2$ million per year venture, becoming one of the most active summit-initiated technology-fostering programs. On January 30, the United States and France took the first step toward spinning VAMAS off from the Summit Working Group as an independent, cooperative venture. During a ceremony at the residence of the French ambassador in Washington D.C., representatives of the two nations penned the initial signatures on a "memorandum of understanding" that had beendrawn up by the participating summit nations and EEC.

This memorandum of understanding goes into effect as soon as representatives of
Canada, West Germany, Italy, Japan, the United Kingdom and the EEC add their signatures-probably by May. Not only will this new structure make it easier for the European nations to secure funding for their participation, but it also ensures that VAMAS survives when the Heads of State formally divest themselves of responsibility for all 18 projects later this year, at their next economic summit, in Japan.

VAMAS's principal aims are to stimulate introduction of advanced materials into high-technology products and engineering structures, and to encourage international trade through agreement on codes of practice and performance. Basically, its thrust is to foster research on advanced-materials properties and test methods-before standards for these materials are developed. International cooperation in the development of these data and tests never existed before, points out Bruce W. Steiner of the National Bureau of Standards' (NBS) Institute for Materials Science and Engineering. and a member of VAMAS's steering com- mittee. Ironically, he adds, until VAMAS existed, "those of us in the field were really unaware of how important the need for it had become."

Led jointly by the United States and United Kingdom, the Versailles materials project has already initiated research programs in 11 areas.

\section{Wear Test Methods}

Second only to corrosion as a costly source of materials deterioration, the Organization for Economic Cooperation and Development (OECD) estimates that industrialized countries suffer economic losses due to wear and wear-related phenomena amounting to between 1 and $2 \%$ of their gross domestic product. VAMAS's activities here will be focusing on improving the reproducibility and comparability of weartest methods and characterizing how the wear behavior in "advanced" materialsprimarily ceramics and inorganic coatings-

Continued 
Continued from previous page

differs from that of more conventional materials.

National representatives were so enthusiastic about the importance of this "working area" that at least four laboratories in each country plan to actively participate in round-robin testing of wear-study methods for metals and ceramics. In the United States, Steiner says, "we have 10 or 12 companies taking part." And, as one measure of the significance participants accord these tests, Steiner adds, there is little concern over costs involved. In fact, he points out, "The French simply volunteered to produce (the relatively costly ceramics) for these tests, free of charge," to all participating laboratories.

\section{Surface-Chemical Analysis}

Studies to be conducted in this area will focus on reference materials, data and methods. For example, Canada plans to produce thin films of iron oxide, nickel oxide and chromium oxide having thicknesses of about 25 nanometers. After characterization in other member states, they will be used as reference materials. France plans to develop reference methods and dat a for calibrating and characterizing electron spectrometers. And researchers in the United States and United Kingdom have begun work on a review article summarizing formulas for quantitative surface analyses using electronic spect roscopic methods in different situations (such as samples having absorbed layers, thin films or varying compositions).

\section{Polymer Blends}

These materials are produced from either homogenous or multiphase mixtures of structurally different polymers. Production of these blends is growing rapidly; the U.S. ind ustry was already valued at $\$ 340$ million in 1983. Major growth areas in the near future are expected to include blends that are stable at high temperatures, are electrically conducting, or resist fracturing.

Initial objectives in this study area include selection and acquisition of three tons of polycarbonate and linear low-density polyethylene, preparation of five blends having different combinations of the ingredients, collection of data on the materials' behavior, and round-robin tests.

\section{Polymer Composites}

Though standards already exist for many aspects of glass-fiber and carbon-reinforced composites, much more needs to be done, according to $\mathrm{C}$. Bathias, of the Universite de Technologie de Compiègne in France, who heads VAMAS's activities in this area. Moreover, he says, "the novelty and internal structure of composite materials means that existing scientific and technical knowledge and practice are altogether insufficient to make standardization easy." Initially, this working area will focus on three types of studies: prediction of lifetimes when composites a re subjected to complex conditions (such as multiaxial steady or cyclic stress in agressive environments), prediction of delamination (no precise specifications yet exist for testing and analysis of interlaminar fracture), and use of nondestructive techniques to study defects and damage.

\section{Ceramics}

For many applications, specifications for potential ceramics' performance cannot be expressed in terms of the same properties exhibited by the metals they might replace. That's why this program seeks to work toward establishment of standards in relation to ceramics-and not as a mere translation of existing metals standards. Of primary interest are values describing brittle behavior (in relation to time-dependent phenomena) and durability. VAMAS's top priorities include studying: thermal-shock resistance, chiefly for cyclic conditions; mechanical strength-mostly under static, long-duration loading; and frictional properties, including wear.

\section{Hot Salt Corrosion Resistance}

Gas turbines in aircraft and ships in marine environments suffer from severe corrosion as a result of exposure to a combination of salt and sulfurous contaminants in fuel. This program seeks to evaluate the corrosion resistance of individual alloys and the test methods used to provide those data. A goal is to formulate and recommend a standard test procedure.

\section{Weld Characteristics}

There exists no reliable model for calculating weld toughness from its geometry, the pattern of stress to which it's subjected and localized properties, nor are there reliable methods for testing a weld as a whole. One of the goals of this group will be to characterize fracture toughness of welded joints in steel. In addition, the program will measure the surface tension of liquid steel using a range of techniques, model metalflow and arc physics, and conduct trial welds. Its aim is to develop a compositional standard for improving the consistency of weld penetration during automatic welding with the tungsten-inert-gas (TIG) technique.

\section{Superconducting and Cryogenic Materials}

A new working area, research here will focus on the development of standards for superconducting and cryogenic materials used in the liquid-helium temperature regime. Topics being considered for cooperative collaboration under VAMAS include: characterizing reference superconductors to clarify effects of component purity and fabrication on materials performance; establishing methods to measure losses and strain effects in superconductors; developing methods to test mechanical, thermal, magnetic and electric properties of cryogenic structural materials (at low temperatures); establishing standard radiation-effects tests for these materials; and developing methods for measuring "critical" values-including field, current and temperature-at the point where a material becomes superconducting.

The properties of materials used for substitution of human-body parts cannot be predicted based on their properties in more normal environments. Bones adjust to stress. The body will try to reject implanted materials. Such factors suggest why the conditions implant materials must be engineered to work under are hard to model. This new working group will focus on four topics: materials in contact with hard tissues, materials in contact with soft tissues, materials in contact with blood, and materials for biotechnology.

High-Temperature Mechanical Properties

Added only at the last VAMAS meeting in Montreal, last September, this program plans to study creep-crack growth-the study of how small defects in forgings and castings foster the development of slowgrowing cracks in high-temperature materials, primarily alloys.

\section{Factual Materials Databanks}

Also added at the September meeting, this program aims to list parameters for which standards must be established-both for individual materials and for the way such data should be stored in computer databanks. Measurements on wear, melting points, structural features and the nature of chemical changes at different temperatures are among the advancedmaterials data being recorded in computerretrieval systems. However, Steiner notes, "that computerization process is taking different forms. If we simply left matters to take their course, it would be very difficult, if not impossible, to intercompare (the data they hold) automatically." Because of the urgency in resolving these differences, this program has one of the shortest timetables. Steiner says the U.S., Europeans and Japanese are all expected to report their recommendations at a September meeting in Tokyo.

JANET RALOFF

MRS

\section{ANET RALOFF}

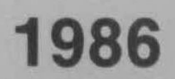

MRS

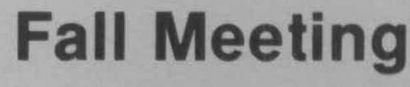

December 2-7, 1986

Boston, Massachusetts

See Call for Papers

in this issue. 